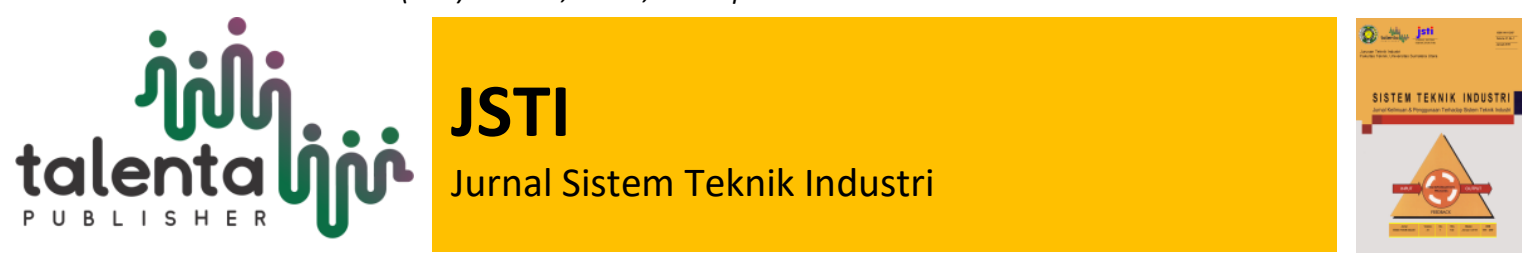

\title{
Mengukur Potensi Bahaya dan Resiko Kecelakaan Kerja dengan Metode Hazard and Operabillity Study pada Aktivitas Maintenance
}

\author{
Dede $^{1}$, Winarno ${ }^{2}$ \\ ${ }^{1,2}$ Program Studi Teknik Industri,Fakultas Teknik,Universitas Singaperbangsa Karawang
}

\begin{abstract}
Work accidents are things that must be avoided, so that's not inflicted loss on the company and the workers. However, several workers still not pay attention to occupational health and safety regulations and in the work area still found several potential hazards. The research is conducted at PT Pindo Deli Pulp and Paper Mills Indonesia in Karawang Regency and focuses on preventive and corrective maintenance activities that prevent paper machine breakdown. The purpose of this study is to measure how big the potential hazard and impact by using Hazard and Operability Study (HAZOP) method. This method is a systematic study, which aims to find the factors that causing work accidents and find out how big the potential accidents and their impacts. The data is collected by distributing questionnaires to the employee. The results show that hazards caused by the work area and the workers themselves are $18 \%$ and $82 \%$, respectively. Based on the severity, the number of extreme, high, medium and low risk hazards are $1,8,1$ and 1 , respectively..
\end{abstract}

Keyword: Hazard Identification, Risk Assesment, Risk Matrix, HAZOP Method, Maintenance

\begin{abstract}
Abstrak. Kecelakaan kerja merupakan hal yang harus dihindari agar tidak merugikan perusahaan dan pekerjanya sendiri. Namun, Masih ada pekerja yang kurang memperhatikan peraturan kesehatan dan keselamatan kerja di tempat kerjanya dan ditemukan beberapa potensi bahaya di area kerjanya. Penelitian dilakukan pada PT Pindo Deli Pulp and Paper Mills Indonesia di Kabupaten Karawang. Penelitian berfokus di dua kegiatan pemeliharaan yaitu pemeliharaan preventif dan korektif yang dilakukan untuk mencegah kerusakan mesin. Tujuan dari penelitian ini adalah untuk mengukur seberapa besar potensi bahaya dan dampak yang akan terjadi. Metode yang digunakan untuk mengukur potensi tersebut adalah dengan metode Hazard and Operability Study (HAZOP). Metode ini merupakan studi keselamatan yang sistematis, yang bertujuan mencari faktorfaktor penyebab kecelakaan kerja dan mengetahui seberapa besar potensi kecelakaan dan dampak yang akan ditimbulkan. Pengumpulan data dilakukan dengan menyebarkan kuesioner kepada karyawan. Hasil perhitungan menunjukkan bahwa terdapat 18\% temuan hazard yang berasal dari lingkungan kerja dan $82 \%$ temuan berasal dari pekerja itu sendiri. Berdasarkan ukurannya, terdapat 1 temuan hazard yang beresiko ekstrim, 8 temuan hazard beresiko tinggi, 1 temuan hazard beresiko sedang dan 1 temuan hazard beresiko rendah.
\end{abstract}

Kata Kunci: Identifikasi Bahaya, Penilaian Resiko, Risk Matriks, Metode HAZOP, Perawatan

Received 02 May 2021 | Revised 09 July 2021 | Accepted 14 July 2021

*Corresponding author at: Universitas Singaperbangsa Karawang, Karawang, Indonesia

E-mail address: dede.dede17013@student.unsika.ac.id 


\section{Pendahuluan}

Sistem manajemen K3 juga dinyatakan menurut Undang-Undang No. 13 Tahun 2003 tentang Ketenagakerjaan pada pasal 86 dan pasal 87. Dalam pasal 86 undang-undang tersebut menjelaskan bahwa setiap pekerja / buruh mempunyai hak untuk memperoleh perlindungan atas $\mathrm{K} 3$, perlindungan atas moral dan kesusilaan, dan perlakuan yang sesuai dengan harkat dan martabat manusia serta nilai-nilai agama. Sedangkan dalam pasal 87 menyebutkan bahwa setiap perusahaan harus menerapkan sistem manajemen $\mathrm{K} 3$, untuk diintegrasikan dalam sistem manajemen umum perusahaan. Selain itu perusahaan berkewajiban untuk menanggung seluruh biaya pekerja yang mengalami kecelakaan. Keselamatan dan Kesehatan Kerja (K3) merupakan salah satu faktor penting dalam kelancaran produksi sehingga program tersebut harus diterapkan di perusahaan dan bukan hanya sekedar wacana. Kecelakaan kerja merupakan kecelakaan yang terjadi dalam lingkungan kerja yang dapat terjadi karena kondisi lingkungan kerja yang tidak aman ataupun karena human error [1] [2].

Penelitian dilakukan pada PT Pindo Deli Pulp and Paper Mills Indonesia dengan berfokus pada potensi bahaya dan dampak yang ditimbulkan pada kegiatan preventive dan corrective maintenance yang dilakukan pada paper machine. Adapun struktur kegiatan maintenance yang dilakukan pada paper machine dapat dilihat pada Gambar 1 dapat dilihat bahwa terdapat dua jenis kegiatan maintenance yang dilakukan yaitu planned (direncanakan) dan unplanned (tidak direncanakan) maintenance.

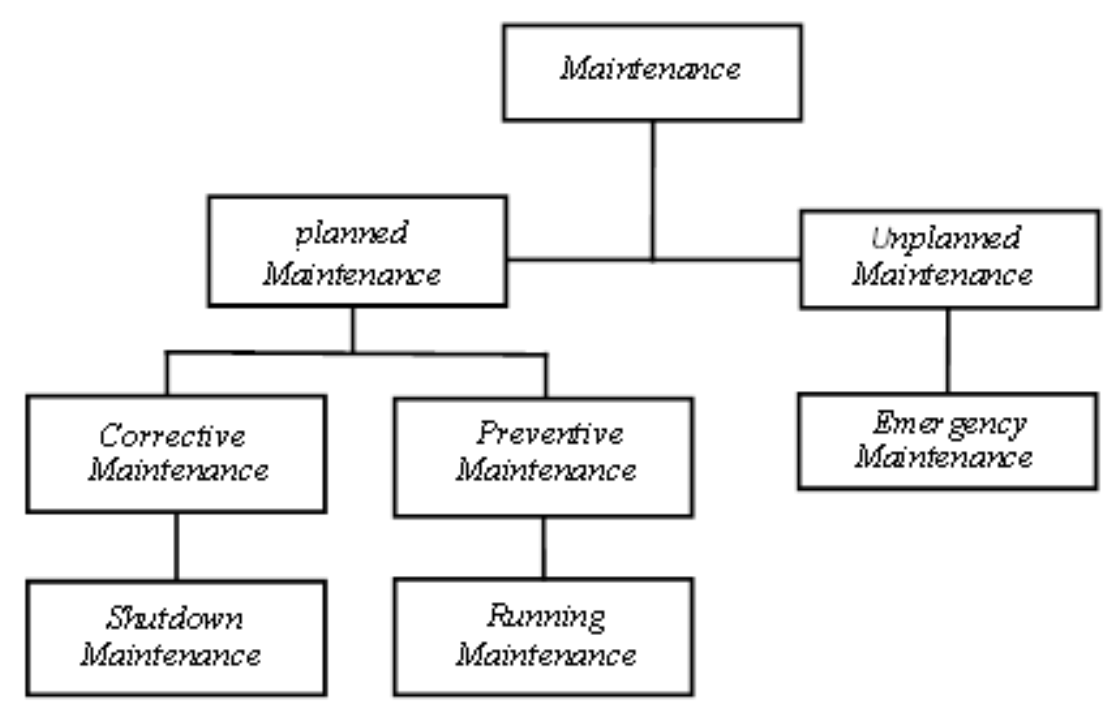

\section{Gambar 1 Struktur Kegiatan Maintenance}

Preventive maintenance dilakukan secara rutin setiap hari. Kegiatannya antara lain pengecekan suhu, suara, getaran dan pelumasan. Planned maintenance bukan hanya preventive maintenance, ada juga corrective maintenance yang dilakukan pada spare part mesin di area workshop untuk melakukan perbaikan komponen mesin. Dalam pelaksanaan kegiatan maintenance, masih terdapat hal-hal yang berpotensi mengakibatkan kecelakaan kerja baik dari faktor lingkungan dan pekerjanya itu sendiri. Selama mengikuti kegiatan tesebut, masih ada pekerja yang kurang disiplin dalam penggunaan APD seperti pelindung kepala, pelindung mata, 
masker,sarung tangan, dan pelindung kaki. Selain itu, pada area kerja masih terdapat potensi bahaya seperti genangan air yang dapat menimbulkan bahaya untuk pekerja. Oleh karena itu, untuk mengukur potensi bahaya yang dapat menyebabkan kecelakaan di tempat kerja maka diperlukan suatu manajemen resiko yang kegiatannya meliputi identifikasi bahaya, analisis potensi bahaya, penilaian resiko, pengendalian resiko, pemantauan dan evaluasi. Dalam proses identifikasi dan melakukan analisis potensi bahaya tersebut maka dapat dilakukan dengan menggunakan metode Hazard and Operability Study (HAZOP) [3] [4].

HAZOP secara sistematis mengidentifikasi setiap kemungkinan penyimpangan dari kondisi operasi yang telah ditetapkan dari suatu plant. Pemilihan metode HAZOP untuk menganalisis potensi resiko kegiatan maintenance karena berkaitan dengan jalannya proses produksi dan di dalamnya terdapat resiko pada suatu peralatan yang merugikan bagi manusia/fasilitas pada sistem. penelitian ini bertujuan untuk mengukur besarnya resiko kecelakaan kerja yang terjadi pada aktivitas maintenance paper machine di PT Pindo Deli Pulp and Paper Mills Indonesia dan memberikan usulan tindakan pengendalian dan pencegahan terhadap bahaya yang berpotensi terjadi pada area kerjanya. Metode ini juga digunakan sebagai upaya pencegahan sehingga proses yang berlangsung dalam suatu sistem dapat berjalan lancar dan aman [5].

\section{Tinjauan Pustaka}

Alat Pelindung Diri (APD) merupakan alat pelindung tubuh yang berfungsi untuk mengisolasi tubuh tenaga kerja dari bahaya pada tempat kerja dan untuk mencegah terjadinya kecelakaan yang disebabkan oleh berbagai faktor yang ada atau terjadi dalam suatu pekerjaan [6]. Peraturan perundang-undangan yang mengatur penggunaan APD salah satunya adalah Peraturan Menteri Tenaga Kerja dan Transmigrasi Nomor 01/Men/1981,disebutkan dalam pasal 4 ayat 3, bahwa pengurus wajib menyediakan secara cuma-cuma semua alat perlindungan diri yang diwajibkan penggunaannya oleh tenaga kerja yang berada dibawah pimpinannya untuk mencegah penyakit akibat kerja.

HAZOP merupakan gabungan kata hazard dan operability study. Hazard merupakan kondisi fisik yang berpotensi menyebabkan kerugian, kecelakaan, bagi manusia, dan atau kerusakan alat, lingkungan atau bangunan. Sedangkan Operability Study merupakan beberapa bagian kondisi operasi yang sudah ada dan dirancang namun kemungkinan dapat menyebabkan shutdown atau menimbulkan serangkaian insiden yang merugikan perusahaan [7].

Metode HAZOP digunakan sebagai metode untuk meninjau suatu proses atau operasi pada suatu sistem secara sistematis untuk menentukan apakah proses penyimpangan dapat mendorong ke arah kejadian atau kecelakaan yang tidak diinginkan. HAZOP secara sistematis mengidentifikasi setiap kemungkinan penyimpangan dari kondisi operasi yang telah ditetapkan dari suatu plant, mencari berbagai faktor penyebab yang memungkinkan timbulnya kondisi abnormal tersebut, dan menentukan konsekuensi yang merugikan sebab dan akibat terjadinya penyimpangan serta memberikan rekomendasi tindakan yang dapat dilakukan untuk mengurangi dampak dari potensi resiko yang telah berhasil diidentifikasi [8] [9]. 
Berdasarkan penelitian terdahulu, HAZOP berfokus pada keseluruhan proses maupun aktivitas yang menunjang proses produksi di suatu perusahaan. Seperti penelitian yang telah dilakukan oleh S. P. Aprilia, B. Suhardi, and R. D. Astuti (2020) penelitian dilakukan pada unit produksi. B. N. Pujiono, I. P. Tama, and R. Y. Efranto (2019) penelitian dilakukan pada Paper Machine. E. Jamilah, Y. H. Yadi, and A. Umyati (2013) penelitian dilakukan pada area boiler. Untuk penelitian ini, penulis menerapkan HAZOP untuk mengukur potensi bahaya pada kegiatan maintenance.

\section{Metodologi Penelitian}

Permasalahan yang dibahas dalam penelitian ini yaitu tentang potensi resiko kecelakan kerja yang berpotensi terjadi pada kegiatan preventive dan corrective maintenance di PT Pindo Deli Pulp and Paper Mills Indonesia. Pendekatan yang digunakan adalah pendekatan kuantitatif menggunakan data primer yang diperoleh dari sebaran kuesioner yang memuat penilaian resiko kepada pekerja yang terlibat pada kegiatan maintenance. Data yang diperoleh yaitu besarnya potensi resiko dan dampak kecelakaan kerja. Adapun langkah-langkah penelitian dimuat seperti pada Gambar 2.

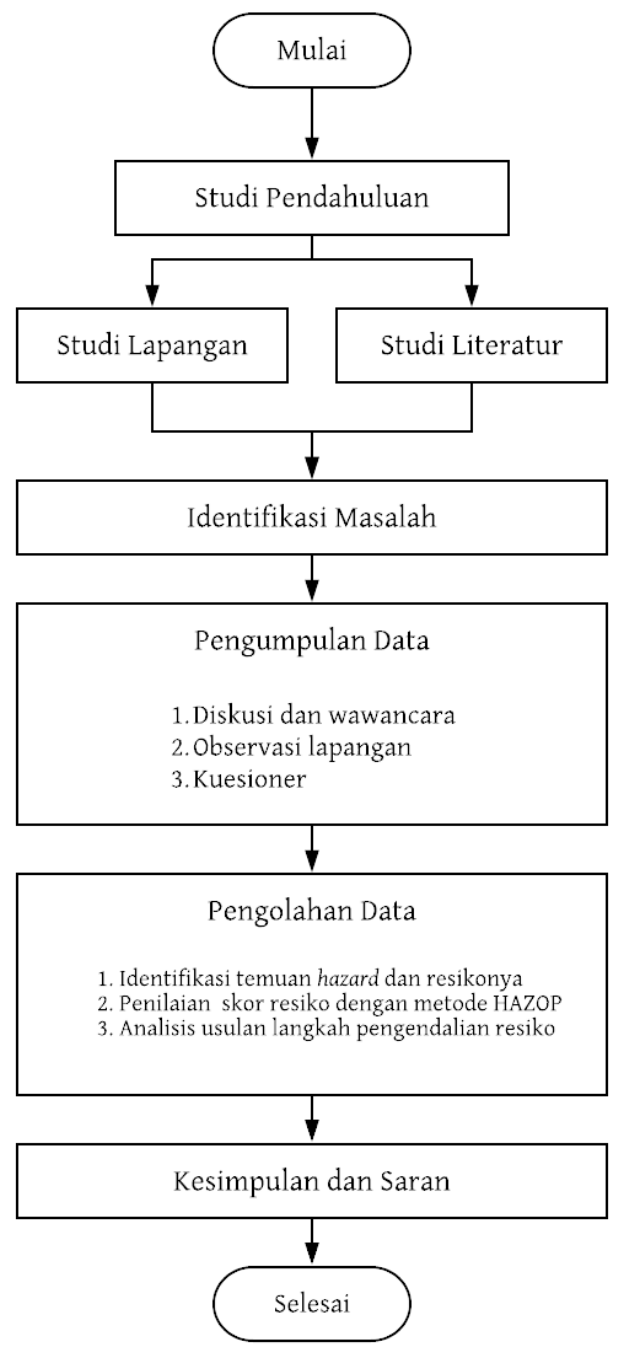

Gambar 2 Flowchart Tahapan Penelitian 
Metode HAZOP dilakukan dengan mengikuti langkah-langkah sebagai berikut [10] [11].

1. Menguraikan temuan hazard dan resiko pada aktivitas maintenance.

2. Menentukan kriteria likelihood dan consequence, kriteria likelihood dan consequence yang digunakan masing-masing adalah frekuensi di mana kejadian sering terjadi dan akibat yang akan diterima pekerja. Rincian kriteria likelihood dan consequence dapat dilihat pada Tabel 1 dan 2.

Tabel 1 Kriteria Likelihood

\begin{tabular}{cll}
\hline Level & \multicolumn{1}{c}{ Kriteria } & \multicolumn{1}{c}{ Deskripsi } \\
\hline 1 & Jarang terjadi & $\begin{array}{l}\text { Dapat dipikirkan tetapi tidak hanya saat keadaan } \\
\text { ekstrim. }\end{array}$ \\
2 & Kemugkinan kecil & $\begin{array}{l}\text { Belum terjadi tetapi bisa muncul/terjadi pada } \\
\text { suatu waktu. } \\
\text { Seharusnya terjadi dan mungkin telah } \\
\text { menjadi/muncul disini atau ditempat lain. } \\
\end{array}$ Mungkin \\
4 & Kemungkinan besar & $\begin{array}{l}\text { Dapat terjadi dengan mudah, mungkin muncul } \\
\text { dalam keadaan paling banyak terjadi. }\end{array}$ \\
& Hampir pasti & $\begin{array}{l}\text { Sering terjadi, diharapkan muncul dalam } \\
\text { keadaan paling banyak terjadi. }\end{array}$ \\
\hline
\end{tabular}

Tabel 2 Kriteria Consequence

\begin{tabular}{|c|c|c|}
\hline Level & Uraian & Keparahan Cidera \\
\hline 1 & Tidak Signifikan & $\begin{array}{l}\text { Kejadian tidak menimbulkan kerugian atau tidak } \\
\text { menyebabkan cedera pada manusia kehilangan hari } \\
\text { kerja. }\end{array}$ \\
\hline 2 & Kecil & Menimbulkan cidera ringan, kerugian kecil. \\
\hline 3 & Sedang & $\begin{array}{l}\text { Cedera berat dan dirawat dirumah sakit, tidak } \\
\text { menimbulkan cacat tetap, kerugian finansial sedang. }\end{array}$ \\
\hline 4 & Berat & $\begin{array}{l}\text { Menimbulkan cidera parah dan cacat tetap dan } \\
\text { kerugian finansial besar serta menimbulkan dampak } \\
\text { serius terhadap kelangsungan usaha. }\end{array}$ \\
\hline 5 & Bencana & $\begin{array}{l}\text { Mengakibatkan korban meninggal dan kerugian } \\
\text { parah bahkan dapat menghentikan kegiatan usaha } \\
\text { selamanya. }\end{array}$ \\
\hline
\end{tabular}

3. Mengalikan nilai likelihood dan consequence sehingga diperoleh tingkat bahaya (risk level) pada risk matrix. Pada Gambar 3 menampilkan Risk Matrix yang dinyatakan dengan angka dan warna tertentu. 


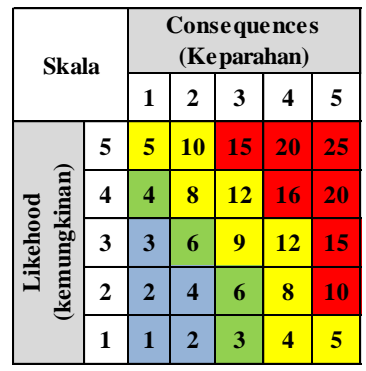

Keterangan :

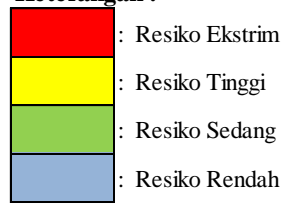

Gambar 3 Risk Matrix

Dari risk matrix tersebut kemudian dapat dihitung skor resiko dan prioritas untuk melakukan tindakan perbaikan. Untuk menghitung skor resiko adalah sebagai berikut.

$$
\text { Skor resiko }=\text { likelihood } \times \text { consequences }
$$

\section{Hasil dan Pembahasan}

\subsection{Uraian Temuan Hazard dan Resiko dalam Aktivitas Maintenance}

Selama mengikuti kegiatan maintenance baik preventif maupun korektif, didapatkan beberapa hal yang berpotensi menimbulkan kecelakaan kerja. Potensi bahaya yang ditemukan merupakan catatan hasil observasi lapangan ketika mengkuti kegiatan maintenance. Dari hasil observasi lapangan didapatkan bahwa 2 (dua) temuan berasal dari area kerja dan 9 (sembilan) temuan berasal dari pekerjanya itu sendiri. Temuan hazard tersebut disajikan dalam Tabel 3.

Tabel 3 Temuan Hazard

\begin{tabular}{|c|c|c|}
\hline No & Temuan Hazard & Potensi Bahaya \\
\hline 1 & $\begin{array}{l}\text { Pekerja tidak menggunakan Alat } \\
\text { Pelindung Diri (APD) secara } \\
\text { lengkap seperti pelindung kepala, } \\
\text { pelindung tangan, pelindung telinga } \\
\text { dan pelindung kaki. }\end{array}$ & $\begin{array}{l}\text { Cedera pada bagian tubuh yang tidak } \\
\text { terlindungi dengan APD. }\end{array}$ \\
\hline 2 & $\begin{array}{l}\text { Pekerja tidak menggunakan helm } \\
\text { keselamatan saat melakukan } \\
\text { preventive maintenance di area yang } \\
\text { terdapat banyak pipa besi yang } \\
\text { tingginya kurang dari } 2 \text { meter. }\end{array}$ & Kepala terbentur pipa besi. \\
\hline 3 & $\begin{array}{l}\text { Pekerja tidak menggunakan helm } \\
\text { keselamatan saat melakukan } \\
\text { corrective maintenance di area } \\
\text { mesin yang terdapat banyak pipa } \\
\text { besi yang tingginya kurang dari } 2 \\
\text { meter. }\end{array}$ & $\begin{array}{l}\text { Kepala tertimpa baut dan mur yang } \\
\text { dilepas dari mesin saat sedang } \\
\text { melakukan corrective maintenance. }\end{array}$ \\
\hline 4 & $\begin{array}{l}\text { Pekerja tidak menggunakan masker } \\
\text { saat di area yang berdebu yang } \\
\text { mengandung Kalsium Karbonat. }\end{array}$ & $\begin{array}{l}\text { Pekerja akan mengalami gangguan } \\
\text { pernafasan dalam jangka yang panjang. }\end{array}$ \\
\hline 5 & Terdapat genangan air di area mesin & $\begin{array}{l}\text { Pekerja akan terpeleset jika genangan air } \\
\text { tersebut sudah sampai berlumut. }\end{array}$ \\
\hline
\end{tabular}




\begin{tabular}{|c|c|c|}
\hline No & Temuan Hazard & Potensi Bahaya \\
\hline 6 & $\begin{array}{l}\text { Pekerja tidak menggunakan } \\
\text { pelindung tangan saat sedang } \\
\text { melakukan proses pelumasan. }\end{array}$ & $\begin{array}{l}\text { Pekerja akan mengalami iritasi kulit } \\
\text { pada telapak tangan. }\end{array}$ \\
\hline 7 & Pekerja tidak memakai sepatu safety & Kaki pekerja tertimpa benda berat. \\
\hline 8 & $\begin{array}{l}\text { Pekerja tidak menggunakan } \\
\text { pelindung telinga saat berada di area } \\
\text { mesin yang. kebisingannya bisa } \\
\text { mencapai lebih dari } 80 \mathrm{db} \text {. }\end{array}$ & $\begin{array}{l}\text { Pekerja akan mengalami gangguan } \\
\text { pendengaran dalam jangka waktu yang } \\
\text { lama. }\end{array}$ \\
\hline 9 & $\begin{array}{l}\text { Pekerja tidak menggunakan safety } \\
\text { belt saat bekerja pada ketinggian di } \\
\text { atas } 1,6 \text { meter. }\end{array}$ & Pekerja terjatuh dan mengalami cedera. \\
\hline 10 & Tidak ada tag card di area listrik. & $\begin{array}{l}\text { Pekerja tersetrum saat sedang } \\
\text { memperbaiki area listrik. }\end{array}$ \\
\hline 11 & $\begin{array}{l}\text { Pekerja tidak menggunakan } \\
\text { pelindung mata saat melakukan } \\
\text { pemotongan besi menggunakan } \\
\text { mesin potong. }\end{array}$ & $\begin{array}{l}\text { Mata pekerja akan kemasukan sepihan } \\
\text { besi yang dapat melukai mata. }\end{array}$ \\
\hline
\end{tabular}

Sebelas temuan hazard dan potensi resikonya tersebut merupakan hal-hal yang kemungkinan akan terjadi ataupun sebelumnya sudah pernah terjadi. Selanjutnya data dari temuan hazard tersebut dijadikan isi kuesioner penilaian untuk mengukur besarnya potensi resiko kecelakaan kerja pada kegiatan maintenance.

\subsection{Perhitungan Skor Resiko dan Risk Level}

Nilai yang digunakan untuk perhitungan skor resiko berasal dari hasil sebaran kuesioner penilaian kepada para pekerja. Kuesioner penilaian tersebut berisi sebelas temuan hazard dengan disertai penilaian likelihood dan Consequence yang diberi rentang nilai dari 1 sampai 5 seperti kriteria likelihood dan Consequence pada Tabel 1 dan 2. Kuesioner tersebut diisi oleh pekerja yang berhubungan dengan kegiatan maintenance. Setelah melakukan penyebaran kuesioner penilaian, kemudian data diolah dengan mengambil rata-rata nilai dari penilaian likelihood dan Consequence dan nilai tersebut digunakan untuk pengukuran besarnya resiko seperti pada Tabel 4 di bawah ini.

Tabel 4 Perhitungan Skor Resiko dan Risk Level

\begin{tabular}{lllcccc}
\hline No & Temuan Hazard & Potensi resiko & Likelihood & Consequence & $\begin{array}{c}\text { Skor } \\
\text { resiko }\end{array}$ & $\begin{array}{c}\text { Risk } \\
\text { Level }\end{array}$ \\
\hline $\mathbf{1}$ & $\begin{array}{l}\text { Pekerja tidak } \\
\text { menggunakan APD } \\
\text { (Alat Pelindung }\end{array}$ & $\begin{array}{l}\text { Cedera pada bagian } \\
\text { tubuh yang tidak }\end{array}$ & 3 & 4 & 12 & Resiko \\
& $\begin{array}{l}\text { Dindungi dengan secara lengkap } \\
\text { (Pelindung kepala, } \\
\text { pelindung tangan, }\end{array}$ & APD. & & & & tinggi \\
& & & & & \\
\hline
\end{tabular}




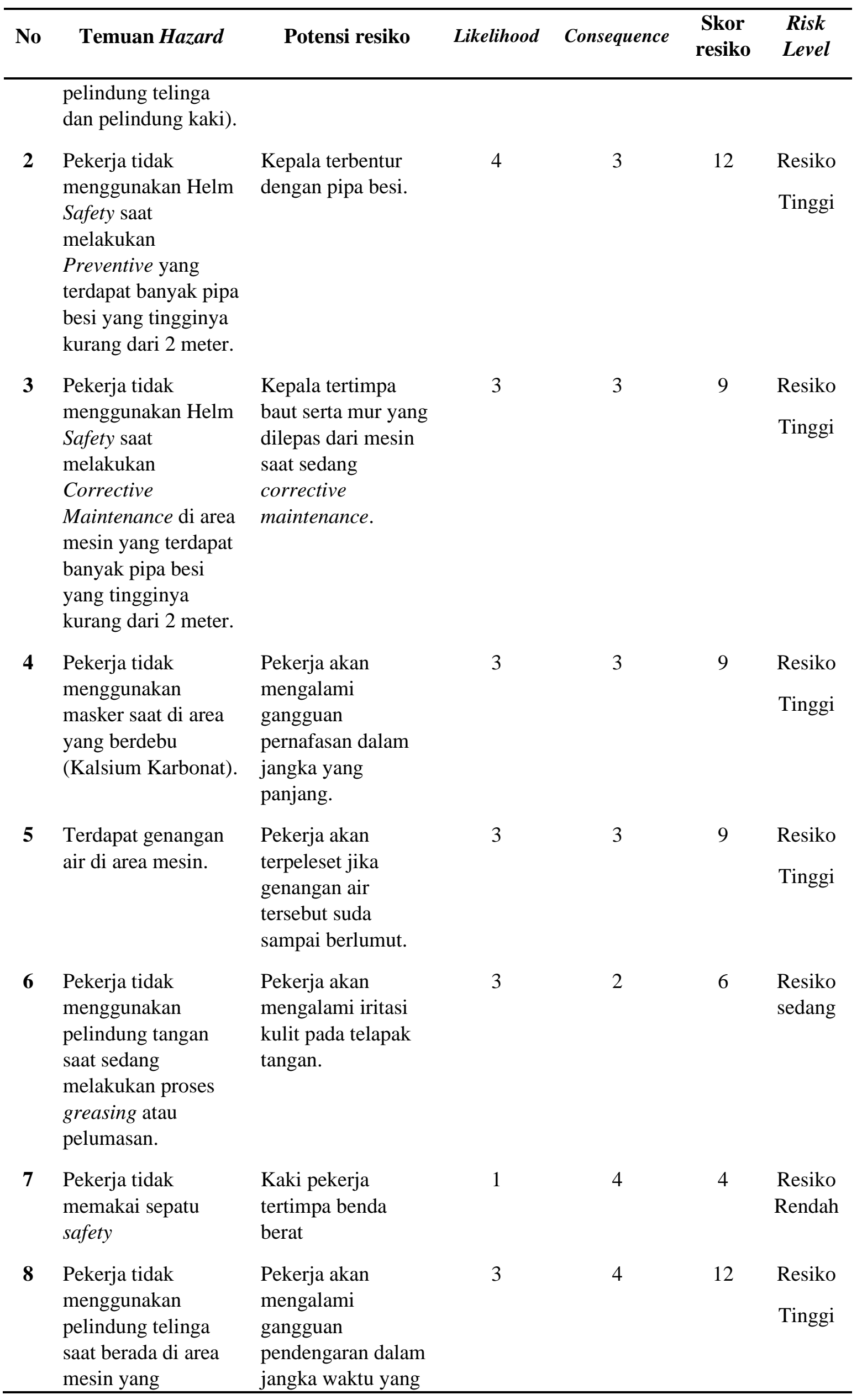




\begin{tabular}{|c|c|c|c|c|c|c|}
\hline No & Temuan Hazard & Potensi resiko & Likelihood & Consequence & $\begin{array}{l}\text { Skor } \\
\text { resiko }\end{array}$ & $\begin{array}{l}\text { Risk } \\
\text { Level }\end{array}$ \\
\hline & $\begin{array}{l}\text { kebisingannya bisa } \\
\text { mencapai lebih dari } \\
80 \mathrm{db} \text {. }\end{array}$ & lama. & & & & \\
\hline 9 & $\begin{array}{l}\text { Pekerja tidak } \\
\text { menggunakan safety } \\
\text { belt saat bekerja } \\
\text { pada ketinggian } \\
\text { diatas } 1,6 \mathrm{~m} .\end{array}$ & $\begin{array}{l}\text { Pekerja terjatuh dan } \\
\text { mengalami cedera. }\end{array}$ & 3 & 4 & 12 & $\begin{array}{l}\text { Resiko } \\
\text { Tinggi }\end{array}$ \\
\hline 10 & $\begin{array}{l}\text { Tidak ada tag card } \\
\text { di area listrik. }\end{array}$ & $\begin{array}{l}\text { Pekerja tersetrum } \\
\text { saat sedang } \\
\text { memperbaiki area } \\
\text { listrik. }\end{array}$ & 3 & 5 & 15 & $\begin{array}{l}\text { Resiko } \\
\text { Ekstrem }\end{array}$ \\
\hline 11 & $\begin{array}{l}\text { Pekerja tidak } \\
\text { menggunakan } \\
\text { pelindung mata saat } \\
\text { melakukan } \\
\text { pemotongan besi } \\
\text { menggunakan mesin } \\
\text { potong. }\end{array}$ & $\begin{array}{l}\text { Mata pekerja akan } \\
\text { kemasukkan gram } \\
\text { besi yang dapat } \\
\text { melukai mata. }\end{array}$ & 3 & 4 & 12 & $\begin{array}{l}\text { Resiko } \\
\text { Tinggi }\end{array}$ \\
\hline
\end{tabular}

Dari tabel 4, didapatkan skor resiko untuk setiap uraian temuan hazard. Tabel 5 menyajikan ringkasan hasil perhitungan dengan disertai simbol warna yang menunjukkan tingkat keparahan untuk masing-masing temuan hazard.

Tabel 5 Ringkasan Hasil Perhitungan Resiko

\begin{tabular}{cccccc}
\hline $\begin{array}{c}\text { Temuan } \\
\text { hazard }\end{array}$ & likelihood & consequence & skor & $\begin{array}{c}\text { Risk } \\
\text { level }\end{array}$ & $\begin{array}{c}\text { Sumber } \\
\text { bahaya }\end{array}$ \\
\hline 1 & 3 & 4 & 12 & tinggi & Pekerja \\
2 & 4 & 3 & 12 & tinggi & Pekerja \\
3 & 3 & 3 & 9 & tinggi & Pekerja \\
4 & 3 & 3 & 9 & tinggi & Pekerja \\
5 & 3 & 3 & 9 & tinggi & Area kerja \\
6 & 3 & 2 & 6 & sedang & Pekerja \\
7 & 1 & 4 & 4 & rendah & Pekerja \\
8 & 3 & 4 & 9 & tinggi & Pekerja \\
9 & 3 & 4 & 12 & tinggi & Pekerja \\
10 & 3 & 5 & 15 & ekstrem & Area kerja \\
11 & 3 & 4 & 12 & tinggi & Pekerja \\
\hline
\end{tabular}




\subsection{Pengendalian Resiko, Pemantauan dan Evaluasi}

Perancangan rekomendasi atau usulan perbaikan dilakukan berdasarkan sumber potensi bahaya yang terjadi. Dalam penelitian ini, diberikan analisis dan rancangan perbaikan berdasarkan sumber bahaya yang berasal dari area kerja dan dari pekerja. Ini bertujuan agar semua permasalahan dari sumber bahaya yang ada didapatkan solusinya. Usulan perbaikan ini adalah langkah pengendalian resiko agar mengurangi tingkat kecelakaan dan mencegah adanya kecelakaan yang serupa lagi dengan sebelumnya. Adapun usulan perbaikannya antara lain :

1. Rekomendasi untuk pekerja. Rekomendasi untuk sikap pekerja yang tidak memenuhi standard dalam keselamatan kerja dan prosedur kerja yang baik adalah berupa pelatihan K3 tentang penggunaan APD yang akan diselenggarakan oleh pihak manajemen. Bagi para pekerja yang yang tidak dapat menghadiri pelatihan akan dikenakan sanksi. Bentuk dari sanksi yang akan dijatuhkan sesuai dengan kesepakatan pihak perusahaan. Membuat worksheet dalam penggunaan APD di area kerja supaya para pekerja dapat langsung membaca apa saja potensi bahaya yang akan mereka alami apabila tidak menggunakan APD.

2. Rekomendasi untuk lingkungan kerja. Untuk genangan air di area kerja, dapat dilakukan pengecekan secara berkala dan pekerja dapat melaporkannya ke atasannya. Selanjutnya Membuat visual display mengenai penggunaan APD pada area kerja yang memiliki potensi-potensi kecelakaan kerja dan membuat SOP penggunaan Alat Pelindung Diri dan semua kartu, rambu ataupun tanda untuk tempat berbahaya harus terpasang dengan semestinya agar tidak terjadi kecelakaan kerja yang merugikan perusahaan dan pekerjanya.

Kegiatan pemantauan dan evaluasi dapat dilakukan seiring dengan berjalannya penerapan usulan perbaikan untuk mengurangi resiko kecelakaan kerja pada kegiatan maintenance.

\section{Kesimpulan}

Berdasarkan hasil identifikasi bahaya dan perhitungan menggunakan metode Hazard and Operabillity Study pada kegiatan preventive dan corrective maintenance, didapatkan bahwa $18 \%$ temuan hazard berasal dari area kerja dan $82 \%$ hazard berasal dari pekerja itu sendiri. Berdasarkan resikonya, terdapat 1 (satu) temuan hazard yang beresiko ekstrim, 8 (delapan) temuan hazard beresiko tinggi, 1 (satu) temuan hazard beresiko sedang dan 1 (satu) temuan hazard beresiko rendah. Resiko ekstrem didapatkan pada kelalaian dengan tidak adanya tag card di area listrik sehingga beresiko membuat pekerja tersetrum saat sedang memperbaiki area listrik. Pengendalian resiko dilakukan dengan membuat rancangan perbaikan untuk temuan hazard yang dibedakan berdasarkan sumber bahaya yang berasal dari area kerja dan dari pekerja itu sendiri. 


\section{REFERENSI}

[1] Undang-Undang Republik Indonesia No. 13 Tahun 2003, "Undang-Undang Republik Indonesia No.13 Tahun 2003 tentang Ketenagakerjaan," Undang-Undang, 2003. http://www.kemenperin.go.id/kompetensi/UU_13_2003.pdf.

[2] B. N. Pujiono, I. P. Tama, and R. Y. Efranto, "ANALISIS POTENSI BAHAYA SERTA REKOMENDASI PERBAIKAN DENGAN METODE HAZARD AND OPERABILITY STUDY (HAZOP) MELALUI PERANGKINGAN OHS RISK ASSESSMENT AND CONTROL (Studi Kasus: Area PM-1 PT. Ekamas Fortuna),” J. Rekayasa dan Manaj. Sist. Ind., vol. 1, no. 2, pp. 253-263, 2013.

[3] D. P. Restuputri, R. Prima, and D. Sari, "ANALISIS KECELAKAAN KERJA DENGAN MENGGUNAKAN METODE HAZARD AND OPERABILITY STUDY ( HAZOP )," pp. 24-35, 2015.

[4] H. Mamduh M, "Risiko, Proses Manajemen Risiko, dan Enterprise Risk Management," in Management Research Review, 2014, pp. 1-40, 2014.

[5] E. Widyawati, PENERAPAN KESELAMATAN KERJA DAN PENCEGAHAN PENYAKIT AKIBAT KERJA PADA PERAWAT DI RUMAH SAKIT. 2020.

[6] Y. Oktriyawan, H. Purnomo, dan N. Oktyajati, "Analisis Pemakaian Alat Pelindung Diri pada Tenaga Kerja Antar-Shift Kerja di Unit Produksi PT. XYZ sebagai Upaya Mengendalikan Risiko di Tempat Kerja”, GIJTSI, vol. 2, no. 01, hlm. 50-59, Jul 2021.

[7] S. P. Aprilia, B. Suhardi, and R. D. Astuti, "Analisis Risiko Keselamatan dan Kesehatan Kerja Menggunakan Metode Hazard and Operability Study (HAZOP) : Studi Kasus PT. Nusa Palapa Gemilang," Performa Media Ilm. Tek. Ind., vol. 19, no. 1, pp. 1-8, 2020.

[8] E. Jamilah, Y. H. Yadi, and A. Umyati, "Identifikasi Potensi Bahaya Dengan Metode Hazard And Operability Study ( HAZOP ) Di Area Boiler PT . XYZ," J. Tek. Ind. Univ. Ageng Tirtayasa, 2013.

[9] M. Nur, "Analisis Keselamatan dan Kesehatan Kerja Menggunakan Metode Hazard And Operability Study ( HAZOP ) Di PT . XYZ," vol. 4, no. 2, pp. 133-138, 2018.

[10] A. Haslindah, I. Idrus, Y. Pongsimpin, and R. Budicalista, "ANALISIS RESIKO BAHAYA PRODUKSI BERDASARKAN FAKTOR LINGKUNGAN KERJAMENGGUNAKAN METODE HAZARD AND OPERABILITY ( HAZOP ).," vol. 14, no. April, pp. 1-4, 2019.

[11] E. Ditya, Y. Savitri, S. Lestariningsih, and I. Mindhayani, "Analisis Keselamatan Dan Kesehatan Kerja ( K3 ) Dengan Metode Hazard And Operability Study ( HAZOP ) ( Studi Kasus : CV . Bina Karya Utama ),” vol. 3, no. 1, pp. 51-61, 2021. 